\title{
Do airline pilots and cabin crew have raised risks of melanoma and other skin cancers?
}

DOI:

10.1111/bjd.17586

\section{Document Version}

Accepted author manuscript

Link to publication record in Manchester Research Explorer

\section{Citation for published version (APA):}

Miura, K., Olsen, C. M., Rea, S., Marsden, J., \& Green, A. C. (2018). Do airline pilots and cabin crew have raised risks of melanoma and other skin cancers? Systematic review and meta-analysis. The British journal of dermatology. https://doi.org/10.1111/bjd.17586

\section{Published in:}

The British journal of dermatology

\section{Citing this paper}

Please note that where the full-text provided on Manchester Research Explorer is the Author Accepted Manuscript or Proof version this may differ from the final Published version. If citing, it is advised that you check and use the publisher's definitive version.

\section{General rights}

Copyright and moral rights for the publications made accessible in the Research Explorer are retained by the authors and/or other copyright owners and it is a condition of accessing publications that users recognise and abide by the legal requirements associated with these rights.

\section{Takedown policy}

If you believe that this document breaches copyright please refer to the University of Manchester's Takedown Procedures [http://man.ac.uk/04Y6Bo] or contact uml.scholarlycommunications@manchester.ac.uk providing relevant details, so we can investigate your claim.

\section{OPEN ACCESS}


DR KYOKO MIURA (Orcid ID : 0000-0002-2805-7522)

DR CATHERINE OLSEN (Orcid ID : 0000-0003-4483-1888)

Article type : Systematic Review

\section{Do airline pilots and cabin crew have raised risks of melanoma and other skin cancers? Systematic review and meta-analysis}

K. Miura ${ }^{1 *}$, C.M. Olsen ${ }^{1 *}$, S. Rea ${ }^{1}$, J. Marsden², A.C. Green ${ }^{1,3}$

1 Population Health Department, QIMR Berghofer Medical Research Institute, 300 Herston Road, Herston, Queensland, 4006 Australia

${ }^{2}$ Queen Elizabeth Hospital, Birmingham B15 2GW, UK

${ }^{3}$ CRUK Manchester Institute and Faculty of Biology Medicine and Health, University of Manchester, Manchester Academic Health Science Centre, Manchester, UK

* KM and CMO contributed equally to this work

Corresponding authors:

Jeremy Marsden, Dept of Dermatology, Queen Elizabeth Hospital, Birmingham B15 2GW, UK Jerry.marsden@btinternet.com

Kyoko Miura, Cancer and Population Studies Group, QIMR Berghofer Medical Research Institute, 300 Herston Road, Herston, Queensland, 4006 Australia

Kyoko.Miura@qimrberghofer.edu.au

Phone: +61(0)738453561

Running head: Melanoma and skin cancers in airline pilots and cabin crew: a review

This article has been accepted for publication and undergone full peer review but has not been through the copyediting, typesetting, pagination and proofreading process, which may lead to differences between this version and the Version of Record. Please cite this article as doi: $10.1111 / \mathrm{bjd} .17586$

This article is protected by copyright. All rights reserved. 


\section{Conflict of interest: None}

Funding: This study was supported by a grant from Melanoma Focus, UK. Melanoma Focus was not involved in the design or analyses of the data or the writing of this paper.

KM was supported by NHMRC Program Grant Nos 552429 \& 1073898.

Disclosures: All authors declare that there is no conflict of interest.

\section{What's already known about this topic?}

- Airline pilots are exposed to cosmic and ultraviolet radiation in their occupations and cabin crews are occupationally exposed to cosmic radiation

- Airline pilots and cabin crews appear to be at significantly increased risk of developing melanoma; pilots are at increased risk of dying from melanoma

\section{What does this study add?}

- Risk of melanoma and other skin cancer is approximately doubled in airline pilots and cabin crew compared with the population; occupational exposure to ultraviolet radiation is unlikely to explain the raised risk

- Causal roles of occupational exposure to ionising radiation, and recreational exposure to ultraviolet radiation, are plausible but there is little supporting evidence

- Almost all relevant evidence is out-of-date and is restricted to the Northern Hemisphere: research is needed that better reflects the occupational environment and recreational behaviour of current pilots and cabin crews

\section{Summary}

Background: Airline pilots and cabin crew are potentially exposed to hazardous ultraviolet (UV) and cosmic radiation that may increase their risk of melanoma and other skin cancers.

Objectives: To establish precise risks of melanoma and keratinocyte cancer (KC) for airline pilots and for cabin crew based on all studies published to date.

Methods: We searched Medline, ISI science citation index, EMBASE, SCOPUS, and CINAHL to June 2018. All studies of melanoma and KC risk and mortality in airline pilots and cabin crew compared with the general population were eligible. Standardised incidence ratios (SIRs) and mortality ratios (SMRs) were pooled using random effects models.

This article is protected by copyright. All rights reserved. 
Results: From 5866 articles, we reviewed 44 full-text articles, of which 12 studies whose data were collected mostly between the 1970s-1990s, were eligible for inclusion. The pooled SIR (pSIR) for melanoma in pilots was 2.03 (95\% confidence interval (CI) 1.71-2.40) and in cabin crew was 2.12 (95\% CI 1.71-2.62). For pilots, pSMR for melanoma was 1.99 (95\% CI 1.17-3.40) and for cabin crew was 1.18 (95\% CI 0.73-1.89). For KC, the pSIR was 1.86 (95\% CI 1.54-2.25) in pilots and 1.97 (95\% CI 1.25-2.96) in cabin crew. There was no evidence of study heterogeneity.

Conclusions: Available evidence shows that airline pilots and cabin crew have about twice the risk of melanoma and other skin cancers compared with the general population, with pilots more likely to die from melanoma. However, most of evidence was collected several decades ago and their relevance to contemporary levels of risk is uncertain.

Airline pilots enjoy substantially better health than the general population: they undergo regular medical examinations and have higher than average socio-economic status ${ }^{1}$. Despite a lower risk of some cancers ${ }^{2,3}$, airline pilots appear to be at significantly increased risk of developing and dying from melanoma ${ }^{4-7}$. A recent survey reported that melanoma rates among airline pilots were about 50 times higher than those of the general adult population (19 per 1000 vs. 0.4 per 1000$)^{6}$. Specific occupational causes such as increased exposure to cosmic ionising radiation ${ }^{8}$, UV radiation ${ }^{9}$, and circadian rhythm disruption ${ }^{10}$ are plausible explanations.

Cabin crew are exposed to the same levels of cosmic radiation as pilots and suffer the same disruption of circadian rhythm, but they are not likely to be occupationally exposed to UV radiation. A recent meta-analysis of published studies of airline pilots and/or cabin crew reported double the incidence of melanoma in both pilots and cabin crew compared with the general population (standardised incidence ratios (SIRs) 2.22, 95\% confidence interval (CI) 1.67-2.93, and $2.09,95 \%$ CI 1.67-2.62 respectively) ${ }^{5}$. In addition, the standardised mortality ratio (SMR) for melanoma was significantly raised among pilots (1.83; 95\% CI 1.27-2.63) though not among cabin crew (SMR, 0.90) ${ }^{5}$. However, this analysis included studies of aviation warfare system operators and military pilots as well as non-airline commercial pilots flying short sectors at lower altitudes. Melanoma was not histologically confirmed in all included studies. Data about risk of keratinocyte cancers (KC) in airline pilots show conflicting results ${ }^{2,11,12}$.

Because of uncertainty about melanoma and $\mathrm{KC}$ risk in airline pilots, we undertook a systematic review and meta-analysis of all relevant studies published to date. We also systematically reviewed all published studies and pooled the risk estimates of melanoma in cabin crew as a comparison group. Finally, to supplement these data, we reviewed the published evidence on KC risk in both airline pilots and cabin crew compared with the general population. All studies included were of histologically-confirmed melanoma and KCs. Since hazardous occupational UV exposure would be restricted to the flight deck and therefore would affect only pilots, we

This article is protected by copyright. All rights reserved. 
hypothesised that their risk of melanoma and $\mathrm{KC}$ compared with the general population would be increased more than the corresponding risk of melanoma and $\mathrm{KC}$ seen in cabin crews.

\section{METHODS}

We followed the Meta-analysis of Observational Studies in Epidemiology guidelines for reviews of observational Studies ${ }^{13}$ and the Preferred Reporting Items for Systematic reviews and MetaAnalysis statement to guide reporting ${ }^{14}$. The review protocol was registered with PROSPERO (CRD42017056234) ${ }^{15}$.

\section{Data sources and searches}

We searched only published studies as unpublished literature is often preliminary ${ }^{16}$. Eligible studies in any language to June 2018 were identified by searching the Medline database using PubMed software, the ISI Science Citation Index using the ISI Web of Science search interface, EMBASE, SCOPUS, and CINAHL.

The four-step search strategy entailed an initial search of the database followed by analysis of the text words contained in titles and abstracts, and of the index terms used to describe relevant articles. A second search using all identified keywords and index terms was then undertaken using the medical subject headings or words such as: pilot, airline, aircrew, flight, flight crew, melanoma, basal cell, squamous cell, skin cancer, skin neoplasms, non-melanoma, keratinocyte ${ }^{15}$. The reference lists of all identified reviews and articles were searched for other additional studies and finally, studies that have been commonly cited in the literature and review articles were included as citation search terms in the ISI Science Citation Index (1990 to present) to identify subsequent studies that had referenced them. Titles and abstracts of all identified articles were reviewed by two investigators to exclude those that were clearly not relevant. Non-English articles were assessed after translation. The full texts of the remaining articles were read independently by two investigators to determine if they met the study inclusion criteria, and any differences were resolved by a third investigator.

\section{Inclusion and exclusion}

Prospective and retrospective cohort studies that in any language reported the incidence of or mortality from melanoma or KC (i.e. BCC or SCC) in airline pilots or cabin crew compared with the general population were included. Only studies with histological confirmation of melanoma were included. For mortality, eligible outcome assessments were record linkage (ICD codes), death registries, death certificates, and physician records. Disagreements were resolved by a third reviewer. When multiple reports were published on the same population or subpopulation, we included in the meta-analysis estimates from the report with the longest follow-up duration or the most comprehensive data. Reasons for excluding studies were recorded.

This article is protected by copyright. All rights reserved. 


\section{Data extraction and quality assessment}

Two reviewers independently abstracted data from identified studies using a standardized data abstraction form, with inconsistencies resolved by consensus. The following information was recorded for each study: study design, location, years of data collection, sources and definition of cohort, definition of exposure (e.g. flying hours, radiation dose), number of cases, person-year duration of follow-up, age of the study population, variables used for statistical adjustment, point estimates (odds ratio, hazard ratio, or standardized incidence or mortality ratio) and 95\% confidence intervals (CIs). Finally, two independent reviewers conducted quality assessment using the Newcastle-Ottawa Quality Assessment Scale ${ }^{17}$ where the score ranges from 0 to 9 with greater score indicating higher study quality.

\section{Data synthesis and analysis}

To pool individual study estimates, we used the method of DerSimonian and Laird ${ }^{18}$ using a random-effects model. We presented pooled standardised incidence ratios (pSIR) and pooled standardised mortality ratios (pSMR) with 95\% confidence intervals. Statistical heterogeneity among studies was assessed using the Q-statistic ${ }^{19}$ and inconsistencies were quantified using the $I^{2}$ statistic ${ }^{20}$. Sensitivity analyses were conducted by excluding each study in turn to examine the effect on the pooled estimate. We also assessed potential publication bias through visual inspection of funnel plots and using Begg's and Egger's tests ${ }^{21,22}$. All statistical analyses were performed using STATA Version 15 (STATA Corporation, College Station, TX).

\section{RESULTS}

The search identified 5866 articles, from which we retrieved 44 full-text articles for review. Of these, 20 were duplicate reports or included overlapping study populations, a further two did not present estimates in comparison with the general population, leaving 12 studies eligible for inclusion 1,2,7,11,12,23-29 (Fig 1; Table 1).

\section{Characteristics of included studies}

Studies were published between 1990 and 2017, and three studies were based in North America $^{12,27,29}$, five in Europe ${ }^{1,2,11,25,28}$ and four were multinational ${ }^{7,23,24,26}$ (Table 1). Ten studies were retrospective cohort $2,7,12,23-29$ and two studies were both retrospective and prospective $\mathrm{e}^{1,11}$. All 12 studies ascertained incidence of or mortality from various relevant registries (e.g. cancer registries). According to the Newcastle-Ottawa Quality Assessment Scale, seven studies scored 71,2,23-26,28, four studies scored 611,12,27,29, and only one study scored $5^{7}$ (Table 1).

This article is protected by copyright. All rights reserved. 


\section{Melanoma incidence and mortality in pilots}

Among the seven studies of incidence of melanoma in airline pilots reported, six studies found an increased risk compared with the general population, with SIRs ranging from 1.76 to $2.291,7,12,25,26,29$ whereas one study reported null association (SIR 0.98$)^{2}$ (Fig 2). Using a random effects model, the estimated pooled SIR (pSIR) for melanoma in pilots was 2.03 (95\% CI 1.71$2.40)$ with no evidence of heterogeneity $\left(\mathrm{I}^{2}=0.0 \%, p=0.84\right)$. On excluding each study in turn, the pSIR ranged from 1.88 (95\% CI 1.51-2.33) (Pukkala et al. ${ }^{26}$ excluded) to 2.17 (95\% CI 1.73-2.

73) (Dos Santos Silva et al. ${ }^{1}$ excluded). There was no evidence of publication bias (Begg $p=0.76$; Egger $p=0.66$ ). There were three studies from Europe (Denmark, Finland, Iceland, Norway, Sweden, and UK) that assessed dose-response ${ }^{1,26,30}$, where level of cosmic radiation exposure was assessed by surrogates: duration of employment ${ }^{26}$, cumulative cosmic radiation exposure ${ }^{30}$, and type of licence and cumulative flight hours ${ }^{1}$. These associations tended to be linear: longer duration of employment, greater cosmic radiation exposure, and longer world flights were associated with increased melanoma risk.

Three studies reported melanoma mortality in pilots $23,28,29$ and all showed increased risk of death compared with the general population with pSMR of 1.99 (95\% CI 1.17-3.40) (Fig 3) and no evidence of heterogeneity $\left(I^{2}=41.6 \%, p=0.18\right)$. On excluding a study at a time, pSMR ranged from 1.56 (95\%CI 1.08-2.25) on excluding the study by Irvine et al. ${ }^{28}$ to 2.84 (95\% CI $1.17-$ 3.40 ) on excluding the Hammer et al. study ${ }^{23}$. There was no evidence of publication bias (Begg $p=0.60$; Egger $p=0.75$ ). Dose-response was assessed by three studies ${ }^{31-33}$, where cosmic radiation exposure was variably assessed by duration of employment ${ }^{31}$, cumulative cosmic radiation (calculated by multiplying a dose/type of aircraft by number of block-hours for each aircraft type and adding these numbers), flight durations ${ }^{32}$, and employment duration (including with a 10 year-lag), cumulative cosmic radiation exposure (summed estimated daily effective doses (using information on a dose/flight duration, frequencies of flights) over the duration of employment) ${ }^{33}$. None of the studies reported a significant dose-response relationship between any of these measures and melanoma mortality in pilots.

\section{Melanoma in cabin crew}

The estimated pSIR for melanoma in cabin crew was 2.12 (95\% CI 1.71-2.62) based on two studies ${ }^{24,27}$ with no evidence of heterogeneity $\left(I^{2}=0.0 \%, p=0.55\right)$ (Fig 4$)$. Analyses of doseresponse were reported in two studies ${ }^{24,27}$. Measures of level of exposure were employment duration $^{24,27}$, age at union entry, flight assignments (domestic vs. international) ${ }^{27}$, and cumulative cosmic radiation exposure as measured by annual radiation dose (using information on route, type and duration of flight) over employment duration ${ }^{24}$; no significant dose-response associations were observed.

Only one study assessed melanoma mortality in cabin crew ${ }^{23}$ and showed no elevation (SMR 1.18 (95\% CI 0.73-1.89)). There was no significant dose-response in relation to duration of employment, cumulative cosmic radiation exposure measured by estimated annual segment

This article is protected by copyright. All rights reserved. 
specific effective dose (using information on flight types and durations) and assumed annual flight hours, cumulative number of time zones crossed, or cumulative time spent working in the standard sleep interval ${ }^{34}$.

\section{Keratinocyte cancer in pilots}

One study that assessed basal cell carcinoma (BCC) incidence in pilots 26 found over a doubling of risk (SIR 2.46 (95\% CI 1.88-3.16)). Pooling four studies that assessed KC incidence in pilots $2,11,12,26$ also indicated an increased risk compared with the general population (pSIR 1.86 (95\% CI 1.54-2.25)) with no evidence of heterogeneity $\left(I^{2}=1.4 \%, p=0.39\right)$ (Fig 5). On excluding each study in turn, the pSIR varied from 1.54 (95\% CI 1.13-2.10) when the study by Pukkala et al. ${ }^{26}$ was excluded to 1.99 (95\% CI 1.59-2.49) when that by Band et al. ${ }^{12}$ was excluded. There was no evidence of publication bias (Begg $p=0.73$; Egger $p=0.16$ ). One study of keratinocyte cancer mortality in pilots ${ }^{23}$ showed no increase in risk (SMR 0.93 (95\% CI 0.15-3.04)).

\section{Keratinocyte cancer in cabin crew}

One study assessed BCC incidence and overall keratinocyte cancer incidence in cabin crew ${ }^{24}$ and found both were approximately twice the corresponding rates in the population (SIRs 2.33 (95\% CI 1.77-3.01) and 1.97 (95\% CI 1.25-2.96) respectively). One study of keratinocyte cancer mortality in male cabin crew based on 8 deaths ${ }^{23}$ showed a raised SMR (8.01 (95\% CI 2.9817.33)) compared with the background population.

\section{Melanoma incidence by body site}

Too few data were available to estimate melanoma incidence for different body sites. Only three studies evaluated melanoma sites in pilots ${ }^{25,26,30}$ and two studies in cabin crews ${ }^{24,35}$ and across these studies melanoma was reportedly increased on all sites relative to the general population in both groups.

\section{DISCUSSION}

A review of all relevant published studies suggests that airline pilots have about twice the risk of melanoma and of keratinocyte skin cancers than the general population. They also appear to be at greater risk of dying from melanoma but not $\mathrm{KC}$ compared with the population at large. Given that solar UV radiation is the main environmental cause of melanoma and $\mathrm{KC}$, these data appear to implicate occupational exposure to UV as a cause. UV is undetectable in the cabins of modern airliners, and flight deck levels are either undetectable or not increased above ground level values $^{36}$ though this might not have been the case for airliners operating in the last century when ultraviolet A (UVA) levels on airline flight decks may have been increased ${ }^{37}$. However, we found that almost all relevant published evidence is out-of-date and reflects the circumstances and patterns of behaviour of pilots and cabin crews in the mid- to late twentieth century rather than those of today's pilots and cabin crews.

This article is protected by copyright. All rights reserved. 
Despite this, risk of melanoma and $\mathrm{KC}$ among cabin crew, is raised to the same degree as pilots and consequently, occupational exposure to increased levels of UVR is unlikely to explain our findings. Both pilots and cabin crew experience disruption of circadian rhythm on long-haul routes. Although this is known to be carcinogenic in experimental animals, evidence is more limited in humans ${ }^{30}$. Moreover, much of the data about cancer incidence in airline pilots has accrued from pilots flying short-haul routes. Consequently, circadian disruption seems unlikely to explain our findings. Diagnostic bias due to regular clinical surveillance could contribute to raised incidence of melanoma and BCC in pilots and cabin crew; however, this would not be expected to be associated with increased melanoma mortality.

Exposure to cosmic radiation is elevated in both pilots and cabin crew although dosimetry shows annual exposure to be below levels currently thought to be hazardous ${ }^{38}$ including to the skin $^{39}$. Although melanoma is a cancer with very low sensitivity to induction by ionizing radiation ${ }^{40}$ and consequently is not included among cancers attributed to ionizing radiation in systematic reviews ${ }^{41}$, 'safe doses' regarding induction of melanoma have not been precisely defined and so current occupational dose limits could not be set to specifically minimise melanoma risk. Moreover, the US National Council on Radiation Protection and Measurements show that pilots have the largest average annual effective dose of all radiation-exposed workers in the US ${ }^{42}$. The data showing a linear relationship between melanoma risk (but not melanoma mortality) and longer duration of employment, greater radiation exposure, and longer world flights is in keeping with this notion, and should be explored further.

The alternative explanation for the raised risks of melanoma and $\mathrm{KC}$ in pilots and cabin crew is recreational exposure to solar UV radiation during recreational activities including during stopovers at final destinations. UV is believed to be the cause of melanoma in white populations living at all latitudes ${ }^{43}$ including most of the melanoma in those living at northern latitudes where all published studies regarding melanoma in pilots to date have been undertaken ${ }^{44}$. There is however no direct evidence to show that airline pilots and cabin crew have increased recreational UVR exposure. In particular, increased UVR exposure during stopovers is not supported by evidence, and many professional pilots consider it improbable (K Burnham and G Cruse, personal communication). Moreover, many of the sectors and destinations included in the published studies were at medium and high latitudes.

A previous systematic review 5 also found a doubling of rates of melanoma in pilots and cabin crew compared with the general population, though this was based on a pooled dataset for pilots that differed from the present pooled data. The earlier review included studies of military as well as airline pilots 45,46 and one without histologically confirmed disease ${ }^{47}$, as well as four study populations ${ }^{48-51}$ that had been covered by the single pooled study of melanoma incidence in national cohorts of pilots from Denmark, Finland, Iceland, Norway and Sweden ${ }^{26}$. For melanoma SMR we included a new study ${ }^{23}$, namely a pooled study of melanoma mortality in cohorts of airline pilots and cabin crew from Denmark, Finland, Germany, Greece, Iceland, Italy, Norway, Sweden, UK and the USA which replaced several previously included studies 28,31 3452 . Finally, the previous review 5 assessed melanoma only, while we additionally assessed other skin cancers.

This article is protected by copyright. All rights reserved. 
There was no evidence of publication bias assessed by Begg's and Egger's tests (all $\mathrm{p}>0.05$ ). Nonetheless, the tests are likely to be underpowered due to the small number of studies included in this meta-analysis, and the results should be interpreted with caution. Further, included number of studies for meta-analysis is small, although three of 12 were large pooled studies. With the exception of melanoma incidence in pilots, four studies or less were included in the meta-analyses and this may have limited our ability to estimate heterogeneity accurately. Although we did not detect heterogeneity, neither did we assume homogeneity and used random effects models to account for between-study variance. In this review, we did not include unpublished literature such as conference Abstracts. However, these sources are often preliminary, final results can change, and unpublished literature is not peer reviewed. A major limitation of this review is the lack of contemporary evidence: two large pooled incidence studies included data from as far back as 1947 and almost all of the data were collected at least 2 to 3 decades ago. Thus, the available evidence has uncertain relevance to today's airline flight crews whose occupational circumstances and recreational patterns are different from those of 20 to 70 years ago. Furthermore, European study populations predominate as the basis of available datasets. One New Zealand study was excluded because the measure of melanoma occurrence was self-reported lifetime prevalence ${ }^{6}$, and so there were no studies from Australasia and relatively few from North America to round out the evidence base, leaving it deficient in coverage of melanoma risk in pilots from highly susceptible white-skinned populations.

In summary, this review of all available evidence suggests that airline pilots and cabin crew are at twice the risk of melanoma and keratinocyte skin cancers as the general population, and also that pilots are at raised risk of death from melanoma. However, the bulk of the relevant evidence is out-of-date as it collectively reflects the circumstances and patterns of behaviour of pilots and cabin crews in the mid- to late twentieth century. Ionising radiation exposure remains a plausible cause, and there is an urgent need for contemporary research on this topic.

\section{References}

1 dos Santos Silva I, De Stavola B, Pizzi C et al. Cancer incidence in professional flight crew and air traffic control officers: disentangling the effect of occupational versus lifestyle exposures. International Journal of Cancer 2013; 132: 374-84.

2 Gudmundsdottir EM, Hrafnkelsson J, Rafnsson V. Incidence of cancer among licenced commercial pilots flying North Atlantic routes. Environmental Health 2017; 16: 86.

3 Moshkowitz M, Toledano 0, Galazan L et al. Incidence of colorectal neoplasms among male pilots. World J Gastroenterol 2014; 20: 9116-20.

4 Hammer GP, Blettner M, Zeeb H. Epidemiological studies of cancer in aircrew. Radiation Protection Dosimetry 2009; 136: 232-9.

5 Sanlorenzo M, Wehner MR, Linos E et al. The risk of melanoma in airline pilots and cabin crew: a meta-analysis. JAMA Dermatol 2015; 151: 51-8.

This article is protected by copyright. All rights reserved. 
6 Sykes AJ, Larsen PD, Griffiths RF et al. A study of airline pilot morbidity. Aviat Space Environ Med 2012; 83: 1001-5.

7 Vågerö D, Swerdlow AJ, Beral V. Occupation and malignant melanoma: a study based on cancer registration data in England and Wales and in Sweden. Br J Ind Med 1990; 47: 317-24.

8 Hammer GP, Zeeb H, Tveten U et al. Comparing different methods of estimating cosmic radiation exposure of airline personnel. Radiat Environ Biophys 2000; 39: 227-31.

9 Sanlorenzo M, Vujic I, Posch C et al. The risk of melanoma in pilots and cabin crew: UV measurements in flying airplanes. JAMA Dermatol 2015; 151: 450-2.

10 Markova-Car EP, Jurisic D, Ilic N et al. Running for time: circadian rhythms and melanoma. Tumour Biol 2014; 35: 8359-68.

11 Milanov L, Dimitrov D, Danon S. Cancer incidence in Republic of Bulgaria aircrew, 19641994. Aviat Space Environ Med 1999; 70: 681-5.

12 Band PR, Spinelli JJ, Ng VT et al. Mortality and cancer incidence in a cohort of commercial airline pilots. Aviat Space Environ Med 1990; 61: 299-302.

13 Stroup DF, Berlin JA, Morton SC et al. Meta-analysis of observational studies in epidemiology: a proposal for reporting. Meta-analysis Of Observational Studies in Epidemiology (MOOSE) group. JAMA. 2000; 283: 2008-12.

14 Moher D, Liberati A, Tetzlaff J et al. Preferred reporting items for systematic reviews and meta-analyses: the PRISMA statement. J Clin Epidemiol 2009; 62: 1006-12.

15 Green AC, Olsen CM, Miura K et al. Risk of melanoma in professional pilots and cabin crew: systematic review and meta-analysis. In: PROSPERO 2017 CRD42017056234. 2017.

16 Cook DJ, Guyatt GH, Ryan G et al. Should unpublished data be included in meta-analyses? Current convictions and controversies. JAMA. 1993; 269: 2749-53.

17 Wells G, Shea B, O'Connell D et al. The Newcastle-Ottawa Scale (NOS) for assessing the quality of nonrandomised studies in meta-analyses. 2018; Department of Epidemiology and Commuunity Medicine, University of Ottawa, Canada; Available at http://www.ohri.ca/programs/clinical_epidemiology/oxford.asp; Accessed 06 Sep 2018.

18 DerSimonian R, Laird N. Meta-analysis in clinical trials. Control Clin Trials 1986; 7: 17788.

19 Hardy RJ, Thompson SG. Detecting and describing heterogeneity in meta-analysis. Stat Med 1998; 17: 841-56.

20 Higgins JP, Thompson SG. Quantifying heterogeneity in a meta-analysis. Stat Med 2002; 21: 1539-58.

21 Begg CB, Mazumdar M. Operating characteristics of a rank correlation test for publication bias. Biometrics 1994; 50: 1088-101.

This article is protected by copyright. All rights reserved. 
22 Egger M, Davey Smith G, Schneider M et al. Bias in meta-analysis detected by a simple, graphical test. BMJ 1997; 315: 629-34.

23 Hammer GP, Auvinen A, De Stavola BL et al. Mortality from cancer and other causes in commercial airline crews: a joint analysis of cohorts from 10 countries. Occup Environ Med 2014; 71: 313-22.

24 Pukkala E, Helminen M, Haldorsen T et al. Cancer incidence among Nordic airline cabin crew. Int J Cancer 2012; 131: 2886-97.

25 Perez-Gomez B, Pollan M, Gustavsson P et al. Cutaneous melanoma: hints from occupational risks by anatomic site in Swedish men. Occup Environ Med 2004; 61: 117 26.

26 Pukkala E, Aspholm R, Auvinen A et al. Cancer incidence among 10,211 airline pilots: a Nordic study. Aviat Space Environ Med 2003; 74: 699-706.

27 Reynolds P, Cone J, Layefsky M et al. Cancer incidence in California flight attendants (United States). Cancer Causes Control 2002; 13: 317-24.

28 Irvine D, Davies DM. British Airways flightdeck mortality study, 1950-1992. Aviat Space Environ Med 1999; 70: 548-55.

29 Band PR, Le ND, Fang R et al. Cohort study of Air Canada pilots: mortality, cancer incidence, and leukemia risk. Am J Epidemiol 1996; 143: 137-43.

30 Pukkala E, Aspholm R, Auvinen A et al. Incidence of cancer among Nordic airline pilots over five decades: occupational cohort study. BMJ 2002; 325: 567.

31 Blettner M, Zeeb H, Auvinen A et al. Mortality from cancer and other causes among male airline cockpit crew in Europe. Int J Cancer 2003; 106: 946-52.

32 Langner I, Blettner M, Gundestrup M et al. Cosmic radiation and cancer mortality among airline pilots: results from a European cohort study (ESCAPE). Radiat Environ Biophys 2004; 42: 247-56.

33 Yong LC, Pinkerton LE, Yiin JH et al. Mortality among a cohort of U.S. commercial airline cockpit crew. Am J Ind Med 2014; 57: 906-14.

34 Pinkerton LE, Waters MA, Hein MJ et al. Cause-specific mortality among a cohort of U.S. flight attendants. Am J Ind Med 2012; 55: 25-36.

35 Linnersjö A, Hammar N, Dammstrom BG et al. Cancer incidence in airline cabin crew: experience from Sweden. Occup Environ Med 2003; 60: 810-4.

36 Cadilhac $\mathrm{P}$, Bouton MC, Cantegril M et al. In-flight ultraviolet radiation on commercial airplanes. Aerosp Med Hum Perform 2017; 88: 947-51.

37 Chorley AC, Baczynska KA, Benwell MJ et al. Occupational ocular UV exposure in civilian aircrew. Aerosp Med Hum Perform 2016; 87: 32-9.

This article is protected by copyright. All rights reserved. 
38 International Commission on Radiological Protection. Radiological Protection from Cosmic Radiation in Aviation. ICRP Publication 132. Ann. ICRP 2016; 45: 1-48.

39 Meier MM, Matthia D. Assessment of the skin dose for aircrew. J Radiol Prot 2017; 37: 321-8.

40 Kheifets L, Green A, Wakeford R. Radiation and Public Health. In: Oxford Textbook of Global Public Health (Detels R, Gulliford M, Karim Q et al., eds), 6 edn. Oxford, United Kingdom Oxford University Press,. 2015; 840-56.

41 Parkin DM, Darby SC. 12. Cancers in 2010 attributable to ionising radiation exposure in the UK. Br J Cancer 2011; 105 Suppl 2: S57-65.

42 National Council on Radiation Protection and Measurements. Ionizing radiation exposure of the population of the United States. In. Bethesda, Md. 2009.

43 Chang YM, Barrett JH, Bishop DT et al. Sun exposure and melanoma risk at different latitudes: a pooled analysis of 5700 cases and 7216 controls. Int J Epidemiol 2009; 38: 814-30.

44 Parkin DM, Boyd L, Walker LC. 16. The fraction of cancer attributable to lifestyle and environmental factors in the UK in 2010. Br J Cancer 2011; 105 Suppl 2: S77-81.

45 Garland FC, White MR, Garland CF et al. Occupational sunlight exposure and melanoma in the U.S. Navy. Arch Environ Health 1990; 45: 261-7.

46 Grayson JK, Lyons TJ. Cancer incidence in United States Air Force aircrew, 1975-89. Aviat Space Environ Med 1996; 67: 101-4.

47 Nicholas JS, Butler GC, Lackland DT et al. Health among commercial airline pilots. Aviat Space Environ Med 2001; 72: 821-6.

48 Hammar N, Linnersjo A, Alfredsson L et al. Cancer incidence in airline and military pilots in Sweden 1961-1996. Aviat Space Environ Med 2002; 73: 2-7.

49 Rafnsson V, Hrafnkelsson J, Tulinius H. Incidence of cancer among commercial airline pilots. Occup Environ Med 2000; 57: 175-9.

50 Haldorsen T, Reitan JB, Tveten U. Cancer incidence among Norwegian airline pilots. Scand J Work Environ Health 2000; 26: 106-11.

51 Gundestrup M, Storm HH. Radiation-induced acute myeloid leukaemia and other cancers in commercial jet cockpit crew: a population-based cohort study. Lancet 1999; 354: 2029-31.

52 Zeeb H, Blettner M, Langner I et al. Mortality from cancer and other causes among airline cabin attendants in Europe: a collaborative cohort study in eight countries. Am J

Epidemiol 2003; 158: 35-46.

This article is protected by copyright. All rights reserved. 
Fig 1. Flow diagram of study selection for meta-analysis of melanoma and skin cancers in professional pilots and cabin crew

Fig 2. Forest plot of pooled studies of melanoma incidence in pilots. Each line represents an individual study result, with the width of the horizontal line indicating $95 \% \mathrm{CI}$, the position of the box representing the point estimate and the size of the box being proportional to the weight of the study. CI, confidence interval; SIR, standardised incidence ratio.

Fig 3. Forest plot of pooled studies of melanoma mortality in pilots. Each line represents an individual study result, with the width of the horizontal line indicating $95 \% \mathrm{CI}$, the position of the box representing the point estimate and the size of the box being proportional to the weight of the study. CI, confidence interval; SMR, standardised mortality ratio.

Fig 4. Forest plot of pooled studies of melanoma incidence in cabin crew. Each line represents an individual study result, with the width of the horizontal line indicating $95 \% \mathrm{CI}$, the position of the box representing the point estimate and the size of the box being proportional to the weight of the study. $\mathrm{CI}$, confidence interval; SIR, standardised incidence ratio; F, female; $\mathrm{M}$, male.

Fig 5. Forest plot of pooled studies of $\mathrm{KC}$ incidence in pilots. Each line represents an individual study result, with the width of the horizontal line indicating $95 \% \mathrm{CI}$, the position of the box representing the point estimate and the size of the box being proportional to the weight of the study. CI, confidence interval; SIR, standardised incidence ratio.

This article is protected by copyright. All rights reserved. 
Table 1. Characteristics of 12 studies included in meta-analysis of melanoma and keratinocyte cancers (KC) among pilots/flight crew and cabin crew

\begin{tabular}{|c|c|c|c|c|c|c|}
\hline First author (year) & Study location & Study period & Study population & Total No. (M/F) & Outcomes & Study quality \\
\hline $\begin{array}{l}\text { Gudmundsdottir } \\
\text { (2017) }\end{array}$ & Iceland & $1955-2015$ & Pilots & $551(551 / 0)^{b}$ & $\begin{array}{l}\text { Melanoma } \\
\text { incidence, KC } \\
\text { incidence }\end{array}$ & 7 \\
\hline Hammer (2014) & $\begin{array}{l}\text { Europe (Denmark, } \\
\text { Finland, Germany, } \\
\text { Greece, Iceland, } \\
\text { Italy, Norway, } \\
\text { Sweden, UK), USA }\end{array}$ & 1989-2004 & $\begin{array}{l}\text { Pilots/flight crew, } \\
\text { cabin crew }\end{array}$ & $\begin{array}{l}\text { Pilots } 36,816 \\
(36,816 / 0) ; \text { Cabin } \\
\text { crew 56,955 } \\
(12,288 / 44,667)\end{array}$ & $\begin{array}{l}\text { Melanoma } \\
\text { mortality, KC } \\
\text { mortality }\end{array}$ & 7 \\
\hline $\begin{array}{l}\text { dos Santos Silva } \\
\text { (2013) }\end{array}$ & UK & 1989-2008 & Pilots/flight crew & $16329(15867 / 462)$ & $\begin{array}{l}\text { Melanoma } \\
\text { incidence }\end{array}$ & 7 \\
\hline Pukkala (2012) & $\begin{array}{l}\text { Europe (Finland, } \\
\text { Iceland, Norway } \\
\text { and Sweden) }\end{array}$ & 1947-1997 & Cabin crew & $\begin{array}{l}10,066 \\
(1,559 / 8,507)\end{array}$ & $\begin{array}{l}\text { Melanoma } \\
\text { incidence, KC } \\
\text { incidence }\end{array}$ & 7 \\
\hline Perez-Gomez (2004) & Sweden & 1971-1989 & Pilots & Not stated c & $\begin{array}{l}\text { Melanoma } \\
\text { incidence }\end{array}$ & 7 \\
\hline Irvine (1999) & UK & $1950-1992$ & Pilots/flight crew & $7,362(7,362 / 0)$ & $\begin{array}{l}\text { Melanoma } \\
\text { mortality }\end{array}$ & 7 \\
\hline Milanov (1999) & Bulgaria & 1964-1994 & Pilots & Not stated c & KC incidence & 6 \\
\hline Band (1996) & Canada & $1950-1992$ & Pilots & $2740(2740 / 0)$ & $\begin{array}{l}\text { Melanoma } \\
\text { incidence, } \\
\text { melanoma } \\
\text { mortality }\end{array}$ & 6 \\
\hline Band (1990) & Canada & $1970-1988$ & Pilots & $913(913 / 0)$ & $\begin{array}{l}\text { Melanoma } \\
\text { incidence, KC } \\
\text { incidence }\end{array}$ & 6 \\
\hline
\end{tabular}

This article is protected by copyright. All rights reserved. 
a Study quality was assessed using the Newcastle-Ottawa Quality Assessment Scale.

b This meta-analysis included part of pilot population ('other' Icelandic commercial pilots $n=265$ ) as other pilots were already included in Pukkala (2003).

c $100 \%$ males 


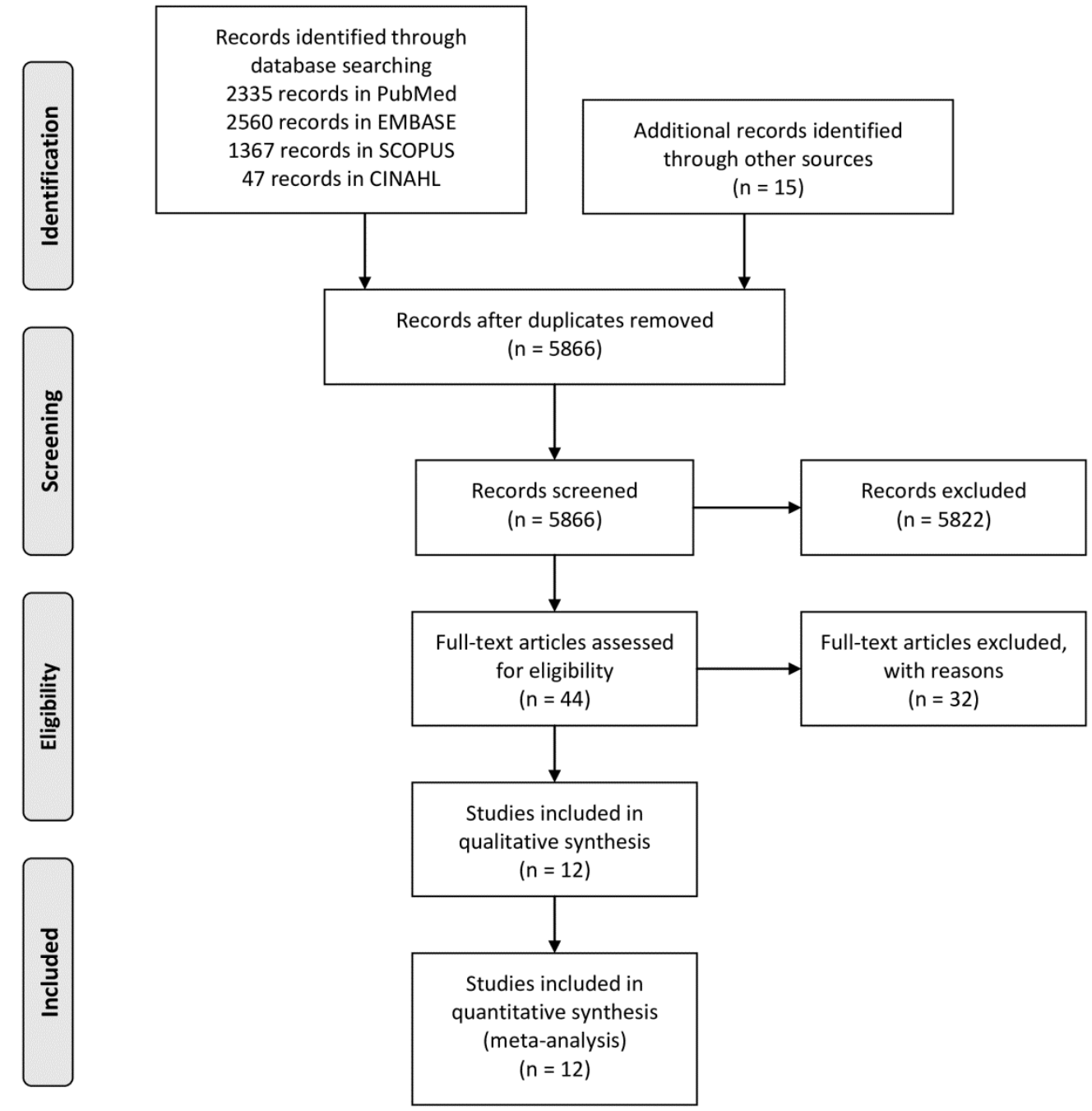

This article is protected by copyright. All rights reserved. 


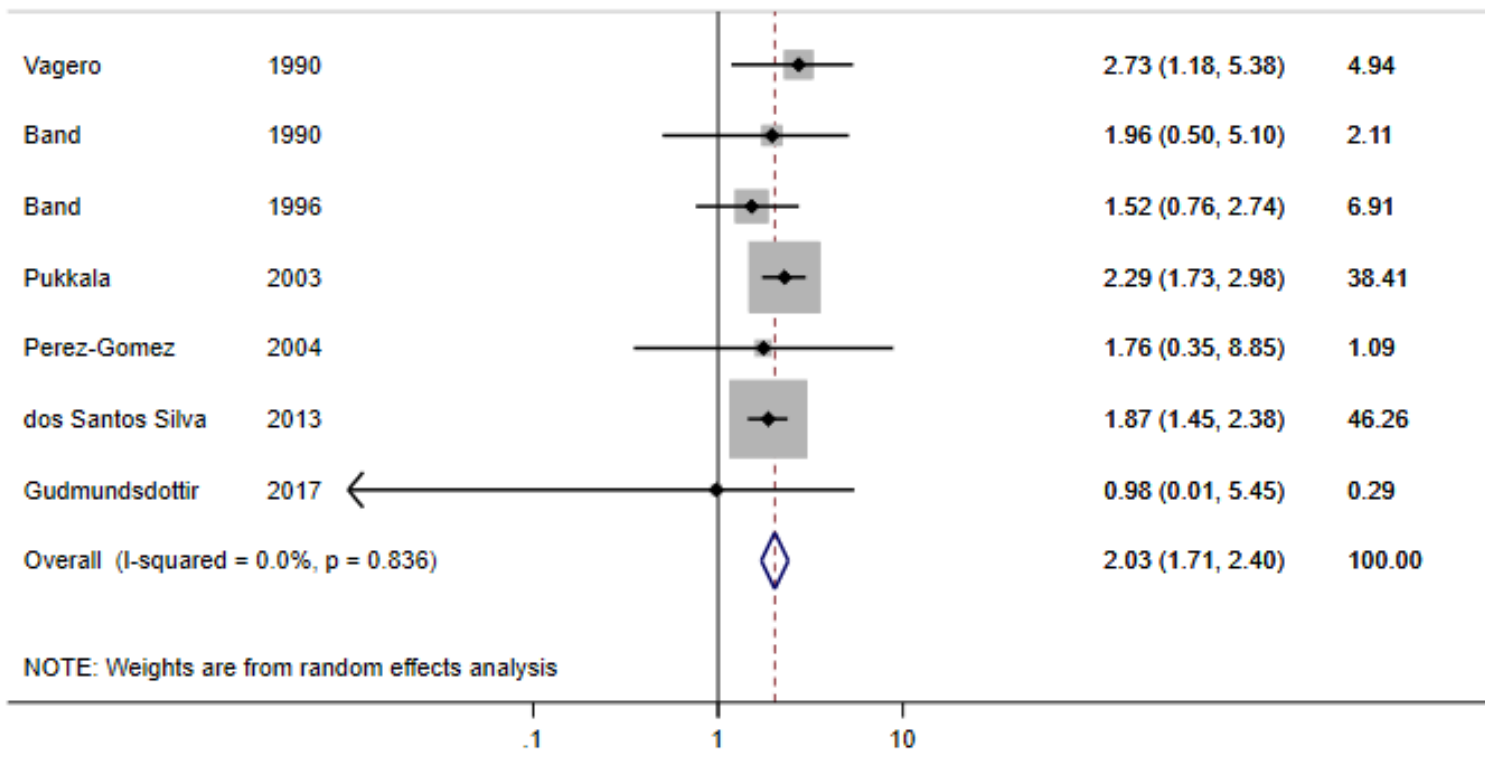

Author Year

pSMR (25\% Cl)

Weight

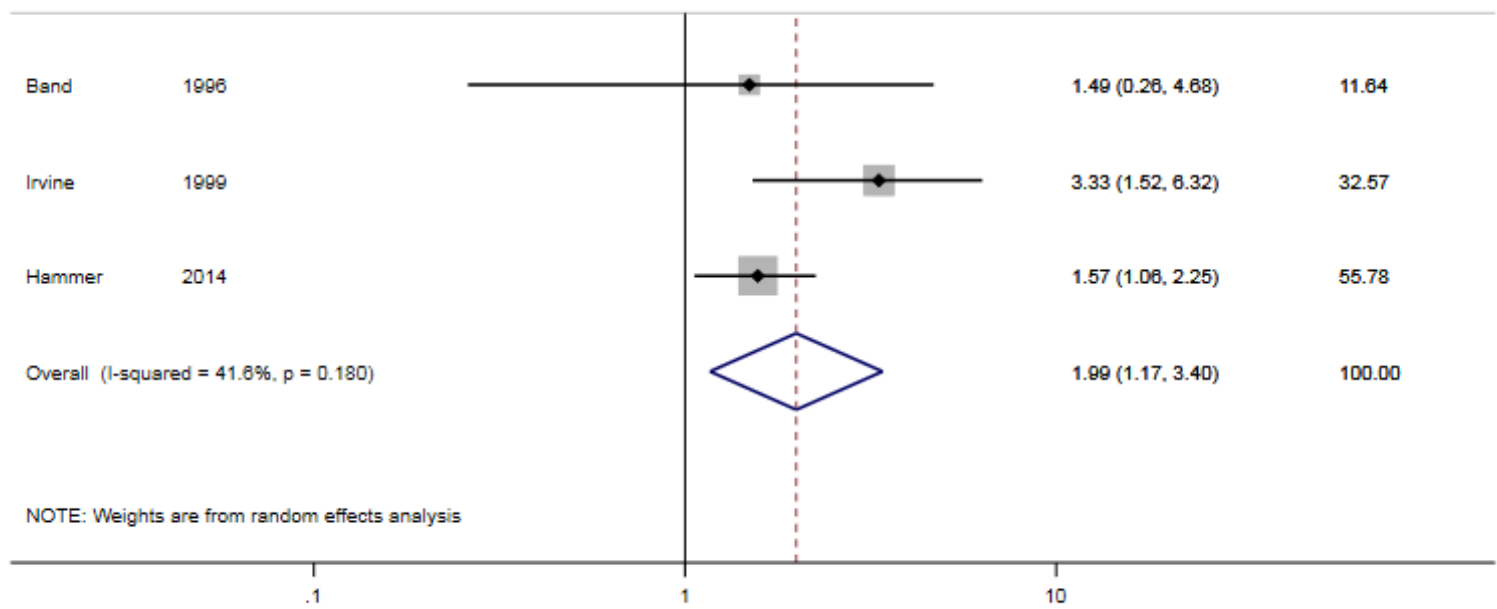

This article is protected by copyright. All rights reserved. 
Weight

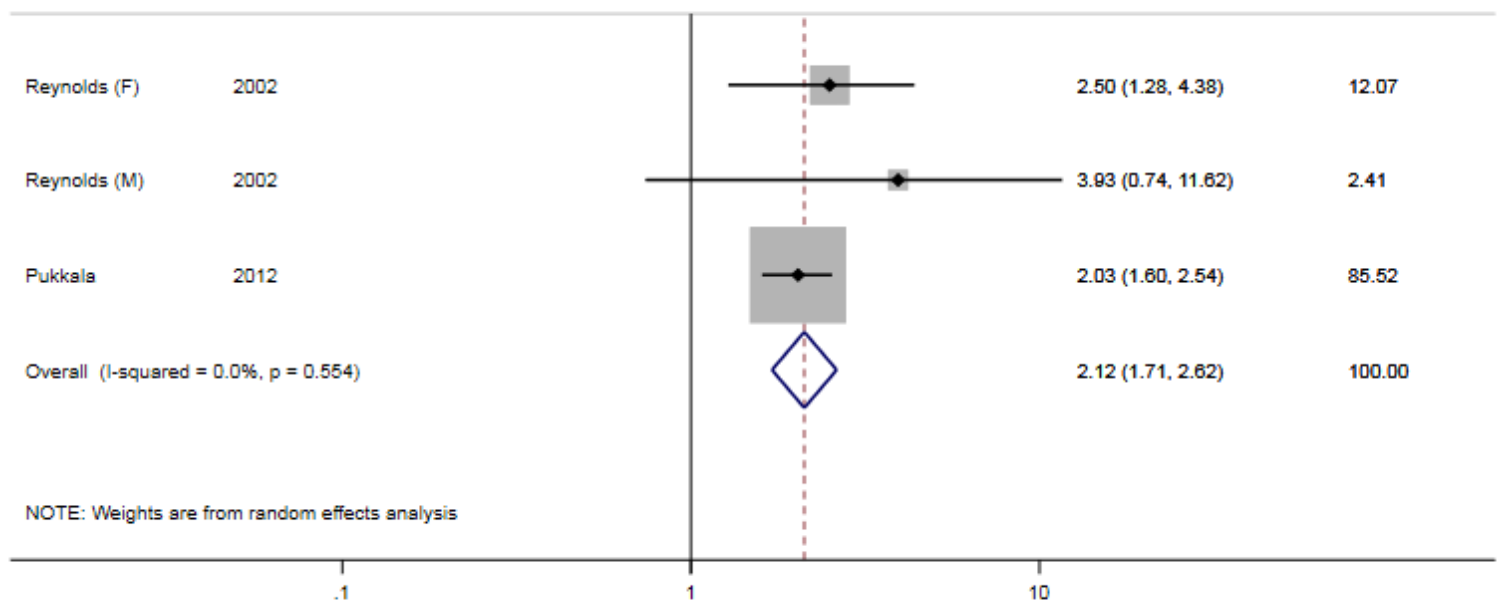

$\%$

Author

Year

SIR $(95 \% \mathrm{CI})$

Weight

Band
Milanov
Sukkala
Overall (l-5quared $=1.4 \%, \mathrm{p}=0.385)$
NOTE: Weights are from random effects analysis

This article is protected by copyright. All rights reserved. 